\title{
LA VIOLENCIA BULLYING EN LAS RELACIONES DE GÉNERO ENTRE ESCOLARES DE NAVARRA'
}

\author{
TEODORO HERNÁNDEZ DE FRUTOS
}

Universidad Pública de Navarra

\begin{tabular}{ll}
\hline PALABRAS CLAVE ADICIONALES & ADDITIONAL KEYWORDS \\
Curriculum, Machismo, Profesores, & Curriculum vitae, Gender, Teachers, \\
Estructura social. & Social Structure.
\end{tabular}

Estructura social. Social Structure.

\begin{abstract}
RESUMEN. El presente artículo da cuenta de una investigación realizada en Navarra sobre el fenómeno de la violencia bullying en estudiantes de la ESO en edades comprendidas entre los 12 y los 16 años, encargada por el Instituto Navarro de la Mujer. Este tipo de agresividad se caracteriza principalmente por ser repetitivo a través del tiempo y a través del mismo agresor y agredido. Además se midieron las relaciones de género dentro del ámbito general de relación entre chicos y chicas, así como las diferenciadas formas de actuar con violencia bullying de unos y otras. Los resultados revelan que estamos ante un hecho que, lejos de desaparecer, todavía es una práctica importante en la vida cotidiana de los centros escolares en Navarra, cuya resolución no supone una manera uniforme de actuar por parte de profesores, y que se produce en lo que se denomina curriculum oculto.
\end{abstract}

' Agradezco a los profesores Stephen Mennell, del University College de Dublin, y a Stephen Heat, de Oxford University, las facilidades que me brindaron durante el verano del 2000 para documentar el presente artículo.

Revista Internacional de Sociología (RIS)

Tercera Época, $n^{\circ} 27$, Septiembre-Diciembre, 2000, pp. 73-103. 
RIS

La agresividad y la violencia son formas de interacción social execrables que desgraciadamente siguen estando presentes en la vida cotidiana de las sociedades avanzadas. Son persistentes en la cultura a través del tiempo y a través de todas las capas sociales, implicando a todas las edades desde el niño más pequeño, siendo consustancial al ser humano en tanto que producto de la naturaleza, al igual que ocurre con otras especies animales. Puede adquirir muchas formas tales, como física, sexual, emocional, verbal, representacional, cognitiva; e incluye la violencia del hombre contra las mujeres y niños, la violencia entre hombres y entre mujeres, la violencia de las mujeres contra niños y hombres, y la violencia de niños contra sus padres y contra adultos. Además admite enfoques teóricos procedentes de la biología, de la psicología, de la psicología social, de las sociología y de la política económica; a través de ellas se ha intentado explicar la violencia procedente de la patología individual, del desarrollo psicodinámico, del estrés, de la frustración y bloqueo de metas, de la teoría de la socialización y del aprendizaje, del proceso familiar, y de las estructuras societales (Fawcett et al., 1996).

A pesar de lo demostrado por J.C. Chesnais (1994), de que la violencia con delitos graves ha disminuido en los países europeos industrializados, se podría mantener que, de los muchos tipos de violencia que todavía persisten, la ejercida contra las mujeres está adquiriendo cada vez mayor protagonismo debido a los constantes maltratos que se producen en el interior de las familias y parejas provocados por los maridos y compañeros. La explicación de la violencia contra la mujer tiene una etiología compleja que no se reduce a una sola variable, pero es posible que entre los variados factores que ejercen una influencia en el fenómeno en sí, la socialización de los hombres violentos en la escuela sea uno de ellos. Lo que se ha denominado como sindrome del encanto o el porqué hombres maravillosos pueden volverse peligrosos amantes ${ }^{2}$, tiene sin duda una explicación en los modelos cognitivos de socialización que han interiorizado en algún momento de su vida emocional. Junto con la familia, la escuela representa el núcleo donde se forjan gran parte de los valores con que nos socializamos; en ésta es en donde además se ejercitan los más variados comportamientos agresivos, algunos de los cuales pueden mantenerse de forma larvada e inconsciente de forma que suponga determinados efectos nocivos en la vida adulta, tales como machismo, xenofobia, insolidaridad, presión grupal sobre los más débiles, etc. (Ortega, 1994).

\footnotetext{
${ }^{2}$ Véase la tesis de S. Horley (2000), "El síndrome del encanto. Por qué hombres encantadores pueden volverse peligrosos amantes", en Generalitat Valenciana (Ed.), Jornadas La violencia del género en la sociedad actual, Valencia, Generalitat Valenciana, pp. 61-81,Valencia.
} 


\section{EL CURRICULUM VISIBLE}

Desde la antigüedad hasta nuestros días, las sociedades han determinado el conjunto de enseñanzas y saberes que son vitales para las generaciones jóvenes a través de un conjunto de materias: es lo que se conoce como curriculum. En España, el curriculum es una parte esencial de la enseñanza, que se encuentra normatizada, en la LOGSE del 3 de octubre de 1990 - la cual estableció la ampliación hasta los dieciséis años de la educación obligatoria y gratuita- en su artículo $4^{\circ}$ apartado $1^{\circ}$ como "El conjunto de objetivos, contenidos, métodos pedagógicos y criterios de evaluación de cada uno de los niveles, etapas, ciclos, grados y modalidades del sistema educativo que regulan la práctica docente"; asimismo, en el apartado $2^{\circ}$ se indica que "El Gobierno fijará, en relación con los objetivos, expresados en términos de capacidades, contenidos y criterios de evaluación del currículum, los aspectos básicos de éste que constituirán las enseñanzas mínimas, con el fin de garantizar una formación común de todos los alumnos y la validez de los títulos correspondientes. Los contenidos básicos de las enseñanzas mínimas, en ningún caso requerirán más del 55\% de los horarios escolares para las Comunidades Autónomas que tengan lengua oficial distinta del castellano, y del $65 \%$ para aquéllas que no la tengan". Igualmente existe una Ley por la que se regula los derechos y deberes de los alumnos de centros de niveles no universitarios (la LODE del 3 de julio de 1985), la cual en su artículo $6^{\circ}$ apartado d), establece: "El derecho a que se respete su integridad y dignidad personales".

En el caso de Navarra, la aplicación de esta norma se ha desarrollado a través de los Decretos Forales 417/1992 y 191/1997. Según el primero de ellos, en su artículo $9^{\circ}$ apartado $1^{\circ}$, "Todos los alumnos tienen el derecho a que se respete su integridad física y moral y su dignidad personal, no pudiendo ser objeto de vejaciones físicas o morales". Además, el Artículo 30 tipifica como faltas leves "Los actos de indisciplina, injuria u ofensa y los actos de agresión física que no tengan carácter de graves"; como faltas graves "La agresión física grave contra los demás miembros de la comunidad educativa", y como faltas muy graves "La agresión física muy grave contra los demás miembros de la comunidad educativa". Todas ellas constitutivas de sanciones de diverso grado e intensidad.

La participación, evaluación y el gobierno de los centros docentes vienen regulada a través de la LOPEG de 20 de noviembre de 1995, en cuyo artículo 11 relativo a las competencias del consejo escolar del centro determina, en su apartado e), que entre sus atribuciones se encuentra "resolver los conflictos e imponer las correcciones con finalidad pedagógica que correspondan a aquellas conductas del alumnado que perjudiquen gravemente la convivencia en el centro, de acuerdo con las normas que establezcan las administraciones educativas", a través de sus respectivos reglamentos de régimen interior. 


\section{EL CURRICULUM OCULTO}

Frente al curriculum visible y a las normas reguladoras de los derechos y deberes de los alumnos y alumnas, se erige lo que se ha denominado como curriculum oculto. La fascinación de éste ha quedado patente en la sociología de la educación de los últimos cincuenta años y sobre todo a partir de las obras de Jackson (1991) y de Bowles y Gintis (1981). Se podría definir como la atmósfera que rodea todas las interacciones en el recinto escolar que no están mediadas o pautadas por una institución o autoridad oficial y superior. Es la constelación de reglas no oficiales (no escritas), pero que proporcionan el sello oficial del centro educativo y que preparan a los niños para el mundo exterior. Es el carácter propio de la institución. Los modos y formas de tratar tanto el mobiliario como al resto de los alumnos, a los profesores y demás personal del centro. Son los derechos y deberes de los estudiantes que no figuran en ninguna parte, pero que se suponen interiorizados. Incluye, de acuerdo con M. Fernández (1995: 115), "todos los mensajes no previstos por la institución escolar que, no obstante, el alumno - y, particularmente en el caso que nos ocupa, la alumnarecibe en la escuela".

Para P. Jackson la escuela llevaría a cabo su papel no de una forma explícita, sino de una manera más difusa, a través de las modalidades organizativas y de las rutinas que imperan en los centros y aulas escolares; es decir, se produce lo que denomina como aprendizaje colateral que es complementario del curriculum explícito: "Casi todos los alumnos aprenden a fijarse en algo y a prestar atención cuando se lo ordenan, a refrenar su fantasía mientras dura la clase. Esta disponibilidad para cumplir las órdenes de la autoridad docente es, por otro lado, doblemente importante porque el alumno tendrá que ejercitarla en muchos lugares extra académicos. El paso de la clase a la fábrica o a la oficina les resulta muy fácil a los que desde sus primeros años han desarrollado hábitos de trabajo" (Jackson, 1991: 48). Para avanzar en forma gradual, para sobrevivir académicamente, los menores de edad deben aprender a estar en silencio, a hacer filas, a esperar, a actuar con interés aunque no estén interesados, a agradar a sus profesores sin alinearse de sus pares, a abordar la inevitabilidad de la escuela: en resumen, a desempeñar el rol de estudiante.

El jardín infantil es la iniciación del niño en la vida escolar, ya que aprenden a hacer lo que quiere el maestro, cuando éste desee que se haga, de manera que hay un tiempo para los cuentos, un tiempo para la siesta y un tiempo para el aprendizaje; es decir un programa oficial cuyo trasfondo es el de imponer la autoridad de una manera pautada y alejarles del mundo particularista de la familia. El alumno debe aprender a relacionarse aceptando aglomeraciones multitudinarias que suponen una gran proximidad con otros compañeros que antes no se conocían, a considerar como naturales y familiares los recintos escolares desde el momento en que penetra en ellos, y sobre todo a acatar un 
ritmo de rutinas donde, en muchas ocasiones, los aspectos de orden y obediencia a las normas que el profesorado establece son lo único que obsesiona a todos los que conviven en estas instituciones. Como argumenta Torres (1996: 61-62): "Los contenidos de los programas son importantes, pero es mucho mayor la preocupación por lograr que niños y niñas se sienten en los lugares asignados, permanezcan en su sitio, sepan esperar, levantar la mano y responder cuando y como el profesorado demanda, saber entrar en fila, guardar silencio, realizar cíclicamente una serie de actividades (por ejemplo, cada día el mismo número de horas de clase, cada hora una materia diferente, y con un orden de asignaturas que casi nunca logra alterarse; cada hora de esas materias a su vez se subdivide en fracciones temporales en las que se realizan regularmente unas tareas escolares determinadas, etc)".

Es lo que se podría denominar como la otra escuela, la otra cara de la moneda, el caldo de cultivo perfecto para que la violencia acampe por sus anchas. En definitiva, un mundo académico y escolar que se desarrolla extraoficialmente, y que poco o nada tiene que ver con el curriculum oficial por el que se evalúa a los alumnos y se les hace partícipes de todo el conocimiento que una instancia superior determina, y en el cual se les exige, en el mejor de los casos, a tener paciencia y, en el peor, a tener resignación, ya que deben aprender a supeditar sus propias acciones al orden establecido. Se les enseña a ser pasivos en determinados momentos, así como a aceptar el conjunto de comportamientos muchas veces injustos en que se encuentran inmersos, lo que conlleva tolerar frustraciones mínimas y aceptar planes y políticas de autoridades injustificadas incluso cuando su razón queda inexplicada y su significado no está claro, de manera que tal como ocurre con los componentes de la mayoría de las demás instituciones fuera de la escuela, aprenden a encogerse de hombros y a decir "así son las cosas".

Ahora bien, no sólo se trata de someter los deseos a la voluntad del profesor, puesto que en la vida extraoficial en muchas ocasiones no se encontrará allí; de lo que se trata en mayor medida es de ajustar las propias acciones a la voluntad de los compañeros más agresivos. En esto las escuelas, como se ha argumentado con frecuenciā, se asemejan a la vida en otras instituciones, en donde impera la ley del más fuerte. En este contexto, la mujer debe amoldarse al trato con los compañeros masculinos cuya característica distintiva es que exhiben mayor fuerza física, más agresividad y una administración de la violencia más contundente: "Entre los informes negativos de la vida escolar predominan dos temas. El primero se refiere a las experiencias aterradoras o embarazosas resultantes de las acciones de profesores y compañeros crueles o insensibles. Tales informes se caracterizan por relatos de castigos extraordinariamente severos y el hecho de convertirse en objeto del ridículo" (Jackson, 1991: 80). Además existe una clara conexión en el proceso de socialización hegemónica de la masculinidad con el empleo de la fuerza física, ya que para mantener las 
RIS

posiciones de poder y privilegio los jóvenes se ven obligados a utilizarla: "En relación con las mujeres y con las niñas, la violencia masculina es también una respuesta estructural, relacionada con el miedo masculino a la intimidad, valor femenino que no forma parte de las actitudes inculcadas a los niños y ante la que se sienten vulnerables e inseguros" (Subirats, 1999: 33).

Si como sostienen Bowles y Gintis (1981) en su teoría de la correspondencia, la institución escolar funciona como una agencia mediante la cual las sociedades capitalistas perpetúan en los jóvenes las estructuras sociales existentes y las relaciones de clase basadas en las necesidades de producción - es decir, preparan a los alumnos para saber comportarse en el futuro en la vida laboral de la fábrica, comercio y oficina-, existiría también una correspondencia entre la estructura del curriculum oculto y las relaciones de género, de manera que la escuela sería la preparación para el mundo del mañana de la mujer en las relaciones de género. En la escuela, las niñas son socializadas de varias maneras, pero es a través del curriculum oculto que aprenden a cómo establecer sus relaciones con el sexo opuesto: un mundo cimentado sobre demostraciones diarias de quién es el que manda, y en definitiva un mundo en donde se aprende a ser sumisa, porque sólo a través de esta actitud se conseguirá una supervivencia cómoda. "Por lo que a la estructura del poder se refiere, las aulas no son demasiado diferentes de fábricas $\mathrm{u}$ oficinas, esas omnipresentes organizaciones en donde transcurre gran parte de nuestra vida de adultos. Así, podría decirse de la escuela que es una preparación para la vida, pero no en el sentido especial en que lo afirman los educadores. Puede que se abuse del poder en la escuela, que es una preparación para la vida, pero es un hecho vital al que debemos adaptarnos" (Jackson, 1991: 73).

Las chicas se encuentran envueltas en una dinámica experiencial que juega negativamente con relación a ellas, toda vez que despliegan conductas específicas para su adaptación a la vida cotidiana dentro de las aulas, que son diferentes a las de los chicos. Si nos acogemos a una categoría como el grado de visibilidad o invisibilidad de cada uno de los miembros que constituyen un grupo de clase, y los categorizamos como visibles e invisibles, según que los profesores y profesoras puedan o no acordarse de ellos una vez terminado el horario docente, las chicas suelen ser las invisibles. De acuerdo a una obra clásica del género, como D. Spender (1983), la escuela refuerza la desigualdad del género en la sociedad a través de las relaciones sociales en el aula, del contenido del curriculum y de las actitudes y expectativas de los profesores, lo cual abunda en la dominación y en el control de los hombres sobre las mujeres; además, las muchachas obtienen menos atención que los muchachos en la clase debido al carácter de éstos y a que la atención que requieren los alumnos por hacerse notar más, desemboca en continuas interrupciones en la marcha de la clase. De acuerdo a esta autora, normalmente los chicos reciben el $60 \%$ del tiempo de los profesores, y es por ello que las mujeres se convierten en invisibles; además, el hecho de que los profesores admitan los insultos y los comentarios abusivos de 
los chicos sobre las chicas refleja la indefensión ante la que se encuentran las estudiantes en el aula y en general en el recinto escolar. En ese mismo año, otra aportación incidió casi en los mismos temas. Stanworth (1983) comprobó que los profesores dan más tiempo y atención a los chicos que a las chicas; ya que cualquier docente es capaz de describir los comportamientos de este tipo de estudiantes una vez terminado su contacto con ellos, los profesores tenían más problemas para recordar a las alumnas que a los alumnos. Tres años más tarde J. French (1986) demostró que los alumnos trasladan sus modelos de comportamiento a la clase, por lo que son más móviles, más activos, más disruptivos y demandan más atención. En España, M. Subirats y C. Brullet (1988), en su estudio sobre la transmisión del código de género en la escuela mixta, llegaron a las mismas conclusiones que las autoras anteriores, denominando al lugar secundario que ocupaban las alumnas en clase como "jerarquía de géneros".

En definitiva y de acuerdo a lo anterior, se podría llegar a la conclusión de que el ser alumna tiene sus riesgos, ya que "podemos comprobar cómo los comportamientos que tradicionalmente vienen siendo más característicos de los niños son más útiles que los etiquetados como femeninos para sobrevivir con éxito en el interior de las aulas" (Torres, 1996), lo que no obsta para que también nos encontremos con el caso del alumnado visible al que se le etiqueta de manera más negativa y con el que se ceban las falsas expectativas. En definitiva, el curriculum oculto se encuentra íntimamente asociado a comportamientos no oficiales, tales como los de agresión entre alumnos y alumnas. La responsabilidad de lo que ocurre en el patio, en los pasillos, en el intercambio entre clase y clase, en el comedor, en las horas previas a la entrada a clase o incluso en las horas posteriores a clase cuando se espera la llegada de los padres o del autocar, en el camino hacia casa, se convierten en espacios de caldo de cultivo para las relaciones desiguales entre alumnos. Un desorden que no se puede controlar y que se sitúa fuera de las horas y obligaciones de los docentes establecidos por la LOGSE.

\section{EL ESTUDIO DEL FENÓMENO BULLYING}

El término bullying hace referencia a un grupo grande y anónimo de personas que se dedican al asedio, o bien se refiere a una persona que atormenta, hostiga o molesta a otra, lo que, llevado al ámbito escolar, supondría que un alumno es agredido o se convierte en víctima cuando está expuesto, de forma repetitiva y durante un tiempo notable, a acciones negativas que lleva a cabo otro alumno o varios de ellos. El término empezó a utilizarse en Suecia y en Noruega a partir del concepto de "mobbing" introducido por Heinemann utilizando la versión sueca de un libro del etiólogo Konrad Lorenz que se refería a un ataque colectivo 
por un grupo de animales sobre un animal de otra especie que constituye un enemigo natural, o a la acción de un grupo escolar contra un individuo desviado del grupo. A partir de aquí D. Olweus (1998: 25) lo aplicará a una conducta específica de escolares: "Una acción negativa es cuando alguien, de forma intencionada, causa un daño, hiere o incomoda a otra persona mediante el contacto físico. Se pueden cometer acciones negativas de palabra, por ejemplo con amenazas y burlas, tomar el pelo o poner motes. Comete una acción negativa quien golpea, empuja, da una patada, pellizca o impide el paso a otro. También es posible llevar a cabo acciones" negativas sin el uso de la palabra y sin el contacto físico, sino, por ejemplo, mediante muecas, gestos obscenos, excluyendo de un grupo a alguien adrede, o negándose a cumplir los deseos de otra persona". Puesto que existe una cierta dificultad para obtener una única definición del término, que en España y Portugal por cierto no existe, se ha llegado a una especie de consenso internacional para definirlo como un concepto que incluye varios elementos claves como: a) ataques o intimidación físicos, verbales, o psicológicos, que están destinados a causar miedo, dolor o daño a la víctima; b) abuso de poder en una relación de poder asimétrica, desde el más fuerte hacia el más débil; c) ausencia de provocación por parte de la víctima; y d) repetidos incidentes entre los mismos niños o jóvenes a través de un prolongado y sostenido periodo de tiempo (Swain, 1998).

Dado que el fenómeno conocido como bullying ha implicado a las administraciones de muchos países, así como a los medios de comunicación y a la opinión pública, haremos un seguimiento del tema contextualizando los estudios con el país en que se desarrollaron.

\section{Estudios pioneros}

Las primeras y más completas investigaciones referidas al fenómeno bullying comenzaron en Suecia a finales de los sesenta y principio de los setenta, a través de Dan Olweus y un estudio longitudinal, que todavía hoy continúa, sobre 3 cohortes de 900 escolares del Gran Estocolmo de $6^{\circ}$ a $8^{\circ}$ curso: los alumnos fueron divididos en agresores, víctimas, bien adaptados y un grupo de control. Las principales variables intervinientes, en tanto que conductas agresivas en los chicos, que se obtuvieron del estudio fueron: el negativismo de la madre, el temperamento del chico, la permisividad materna y los métodos disciplinarios utilizados por el padre y por la madre, tales como el castigo físico y el trato rígido. Se encontró dos tipos de víctimas: los pasivos o sumisos y los provocativos. Los primeros se caracterizaban por ser más débiles físicamente, más ansiosos, más inseguros, más sensibles y más tranquilos, que el resto de los estudiantes en general, con una visión negativa tanto de ellos como de su situación como consecuencia de los ataques sufridos; además, eran solitarios y no tenían buenos amigos en clase. Los segundos se caracterizaban por una combinación de modelos 
de reacción tanto ansiosos como pasivos, con problemas de concentración, hiperactividad, y un comportamiento que causaba irritación y tensión en el grupo donde se encontraban. Sobre los agresores se desprendió que su actitud hacia los profesores era claramente más negativa que la del grupo de control y la del grupo de bien adaptados, y ligeramente más negativa que la del grupo "víctima". Su actitud hacia los compañeros era también más negativa. Eran menos populares que los bien adaptados, pero más que las víctimas. El contacto con los padres era también inferior. Finalmente, algunas características psicosociales diferenciaban a ambos grupos: los agresores se diferenciaban de las víctimas en que tenían menor autoestima y mayor dependencia, su actitud positiva hacia la agresividad era menor y mayor actitud positiva hacia sus profesores, además de que pasaban más tiempo en casa. El hecho de que las repercusiones del estudio coincidieran con algunos suicidios de adolescentes provocó que se inaugurara en la década de los ochenta un programa nacional anti-bullying en el cual se pidió a las escuelas que adoptaran medidas de protección (Olweus, 2000 y 1978).

Estas actuaciones continuaron en Noruega provocados en parte por un hecho ineluctable sucedido en 1982 cuando tres chicos con edades comprendidas entre los 10 y los 14 años se suicidaron, con toda probabilidad como consecuencia del grave acoso al que les sometían sus compañeros de clase, lo cual originó una considerable tensión y desasosiego en los medios de comunicación y en el público en general, y fueron la causa de una cadena de reacciones cuyo resultado final desembocó en una campaña a escala nacional contra los problemas de agresores y víctimas en las escuelas de educación primaria y secundaria a través de un programa que puso en marcha el Ministerio de Educación. Este segundo estudio se llevó a cabo entre 84.000 escolares, de los cuales el $15 \%$ de los alumnos pertenecían a educación primaria y secundaria. Los resultados arrojaron una cifra de 18.000 alumnos sufriendo agresiones "alrededor de una vez por semana" y 10.000 alumnos siendo a la vez agresores y víctimas. Entre las variables intervinientes se encontró una diferencia entre la agresividad intimidatoria de chicos y chicas, un alto absentismo por parte de los profesores, un gran número de agresiones producidas en el colegio frente a otros escenarios (como el camino de ida y vuelta al centro), una mayor conciencia del asunto en los centros urbanos, la no-existencia de correlación entre el tamaño de la escuela y las agresiones, la disminución de las agresiones cuando aumenta el profesorado de vigilancia en el recreo y en la hora de la comida, la poca o nula incidencia en la competitividad de la escuela en los fenómenos violentos, la existencia de dos tipos de víctimas: la pasiva o sumisa (ansiedad y reacción sumisa combinado con debilidad física) y la provocadora (combinación de modelos de ansiedad y reacción agresiva). Finalmente, se observó que cuatro entornos educativos influían en las conductas agresivas: a) la actitud emotiva de los padres hacia el niño, en especial la de la madre, basada en la carencia de afecto y de dedicación; b) el grado de permisividad del primer cuidador del 
niño ante conductas agresivas de éste; c) el empleo, por parte de los padres, de métodos de "afirmación de la autoridad", como el castigo físico y los exabruptos emocionales violentos; d) el temperamento del niño activo y exaltado, y e) la exposición a la violencia en cine, vídeo y televisión (Olweus, 1993).

Los trabajos pioneros llevados a cabo en Gran Bretaña por L. F. Lowenstein (1978) mostraron que los chicos agresores del grupo experimental, si eran comparados con el grupo de control resultaban ser más propensos a tener padres violentos con dificultades maritales, con poca conciencia sobre la educación de sus hijos, con poca dedicación para las relaciones sociales, y con poca o nula sensibilidad hacia los problemas de los demás. Con frecuencia, los componentes de este grupo eran más hiperactivos, disruptivos y extrovertidos, puntuando más alto en neuroticismo, y su registro escolar presentaba unas calificaciones bajas, especialmente en lectura y escritura; mientras, las chicas eran más proclives a utilizar los ataques verbales y psicosociales ${ }^{3}$. Otras aportaciones posteriores, como las de Stephenson y Smith (1988), y Lagerspetz et al., (1982), descubrieron diferencias significativas en el índice de incidencia del fenómeno según la ubicación de la escuela, siendo menor en las del medio rural. E. Roland (1989) encontró que las causas que favorecen el bullying eran el factor poder y el factor afiliación: en la relación de poder entre los individuos se genera el agresor como individuo que utiliza su estatus de poder sobre la víctima, orientado a conseguir sus fines, como necesidad de poder, mientras que la necesidad de afiliación se manifiesta como necesidad de sentirse miembro importante del grupo. Ambos factores se mostraban más rígidos entre chicos que entre chicas, lo que implicaba que los chicos eran agresores de chicos y chicas, mientras que éstas últimas lo eran sólo sobre las chicas. Bjorkqvist, Lagerspetz y Kaukainen (1992) en Finlandia y Ahmand y Smith (1994) en el Reino Unido han clarificado que las diferencias de sexo en la agresión no son tanto físicas versus verbales, sino más bien directas versus indirectas.

En una aportación clásica y seminal, V. Besag (1989) define la conducta bullying como los ataques repetitivos - fisicos, verbales o psicosociales- de aquellas personas que están en posición de poder sobre aquéllas que son débiles frente a ellas, con la intención de causarles dolor en su propia gratificación. Besag establece el marco analítico desde el cual dar explicación del fenómeno, no sin antes resaltar las dificultades derivadas de la complejidad del tema: la dificultad

\footnotetext{
${ }^{3}$ Estos hallazgos han sido confirmados en posteriores estudios por Bowers et al., (1992) "Cohesion and power in the families of children involved in bully/victim problems at school", Journal of Family Therapy, ${ }^{\circ}$ 14, págs. 371-387. Bowers et al., (1994), "Perceived family relationships of bullies, victims and bully/victims in middle childhood", Journal of Social and Personal Relatioships, $\mathrm{n}^{\circ} 11$, págs. 215-232.
} 
de un abordaje empírico para cuestiones tan sensibles, la contaminación de resultados por realizarse in situ con los profesores que conocen bien a sus alumnos y que tratan de suavizar los acontecimientos, y las derivadas de la dimensión del problema, que no puede circunscribirse únicamente al ámbito escolar. Bersag considera que la conducta bullying puede ser entendida como el ataque de un solo individuo hacia otro, como el ataque de un individuo contra un grupo, como el ataque de un grupo contra otro grupo o como el ataque de un grupo contra un solo individuo; pero sólo existirá esta agresión si se produce de manera prolongada en el tiempo frente a un único acto agresivo, si se produce desde el poderoso hacia el débil y si implica agresión verbal, física o psicológica. De ahí deduce Bersag que existirían cuatro facetas del problema: a) puede ser verbal, físico o psicosocial, según su naturaleza; b) puede presentarse bajo la forma de un comportamiento aceptable socialmente, como en la competitividad académica, los deportes o el éxito social, donde en sí mismo hace a otros sentirse inferiores o causar dolor; c) puede ser necesariamente un ataque repetitivo que causa dolor no sólo en el momento del ataque, sino también por la amenaza de futuros ataques; d) puede caracterizarse por el dominio del poderoso sobre el débil en cualquier contexto. Entre los factores ambientales más importantes para ser agresor o agredido figuran los familiares, sobre todo cuando existe una actitud negativa entre padres e hijo (especialmente madre e hijo), cuando existe una sobredisciplina fisica, punitiva o inconsistente y de control laxo, cuando el uso de la agresión física es admitido como socialmente aceptable, cuando existe una relación negativa entre los padres, y cuando se tienen antecedentes familiares problemáticos, como divorcios, alcoholismo, pobreza, falta de afecto maternal y disciplina inconsistente.

\section{Reino Unido}

Inspirado en los resultados obtenidos en Noruega, en 1988 y 1989 se producen varios informes desde el Departamento de Educación del Reino Unido sobre disciplina y relaciones maestro-alumno: el primero, en forma de Circular, y el segundo, con formato de Informe. Este último fue llevado a cabo por Lord Elton, por lo que se le acabaría conociendo como el Informe Elton; en él se dedicaban unos cuantos párrafos al fenómeno bullying al advertir que se trataba de un problema extendido e ignorado por los profesores y que no sólo causaba considerable sufrimiento al alumno individual, sino también al ambiente del colegio. Más tarde, en 1990, se inició un programa en la universidad de Sheffield, subvencionado por la Fundación Gulbenkian y dirigido por I. Whitney y P. Smith, a través de 6.758 alumnos en edades comprendidas entre 8 y 16 años, que completaron una adaptación del cuestionario Olweus, obteniendo para las escuelas secundarias que el $10 \%$ había sido agredido y que el $6 \%$ había abusado sobre otros. El hostigamiento más frecuente fue poner motes, seguido de la 
RIS

violencia física y de las amenazas; las chicas estaban más expuestas a recibir hostigamiento indirecto a través de exclusión social y circulación de rumores maliciosos, que los chicos. El lugar más común era el patio de recreo, y algunas de las víctimas, además de comentárselo al profesor lo había hecho también en su casa, aunque existía una minoría que no lo había hablado con nadie (Whitney y P. Smith, 1993, Whitney et al., 1994). El estudio incluyó dos medidas: un libreto de 32 páginas escrito por Tattum y Herbert (1990) y vendido a bajo precio, y una línea telefónica de ayuda al menor, además de diversas iniciativas e investigaciones.

A esta macroinvestigación le ha seguido otra, realizada desde la Universidad de Keele en 1997 en el Reino Unido, basada en 4.700 entrevistas a alumnos de 11 a 16 años en 25 escuelas secundarias y dirigida por D. Glover et al., (1997 y 2000). Según las conclusiones, el $75 \%$ de los alumnos son hostigados, pero una severa y repetida persecución sólo se produce en el $7 \%$ de los casos. Se identificaron cuatro tipos de comportamientos: agresores, agresores que son también víctimas, víctimas, y no participantes; y cuatro contextos que afectan al alumno en la visión de su propio comportamiento: sí mismo (raza, género, edad, habilidad, o falta de ella, fisica y académica y autoimagen), escuela (tamaño, tipo, organización, apoyo religioso y cultura), hogar (riqueza, valores, cultura, actitudes) y comunidad (valores, cohesión, tensión y recursos). La investigación evidenció que muchos alumnos se encuentran ante una batalla en asegurarse una base firme para vivir en la escuela porque se sienten con falta de apoyo en sus casas, ya que cerca del $24 \%$ respondieron en el cuestionario que sus padres eran estrictos o muy estrictos en el trato. Además, se encontró que la acción bullying sobre el joven, bien por no ser vista o bien por no actuar sobre ella, puede afectar a la autoestima del alumno, así como a su rendimiento escolar.

\begin{abstract}
Alemania
El concepto bullying tiene su correlato en el término gewalt (violencia) o schinkanieren (chinchar, agobiar), y su interés ha supuesto que en los últimos cinco años se hayan realizado más estudios que en los últimos veinte años. Según el estudio de Hurrelman (1994) para la Comisión Gubernamental Independiente para la Prevención y Lucha contra la Violencia de 1990, la violencia se podría definir como la que "abarca todo el espectro de actividades y acciones que causan dolor o lesiones físicas o psíquicas a las personas que actúan en el ámbito escolar, o que persiguen dañar los objetos que se encuentran en dicho ámbito". De acuerdo con Schäfer (1996), entre un 20 y un $30 \%$ de los escolares afirman haber sido agobiados una o dos veces, aproximadamente el $15 \%$ alguna vez, hasta un $2 \%$ por ciento una vez a la semana y del 3 al $6 \%$ varias veces a la semana; del 35 al $45 \%$ de los estudiantes participaron una o dos veces en agobiar a sus compañeros, del 8 al $24 \%$ lo hacen a veces, del 1 al $3 \%$ una vez a la semana
\end{abstract}


y del 1 al $13 \%$ incluso varias veces a la semana. Del análisis de varios estudios a nivel regional, ya que éxisten pocos o ninguno en el ámbito nacional, se pueden extraer las siguientes conclusiones:

- Diferencia relativa entre género de autores y víctimas.

- Aumento de la violencia desde los cursos inferiores a los medios.

- Escasa incidencia de la intimidación en los institutos en comparación con las escuelas primarias o en comparación con otros tipos de escuelas.

- Importancia de la intervención del maestro para su supresión.

- Ignorancia o falta de recursos del profesor para solucionar el problema de la intimidación.

- La intimidación es un problema que hay que tomarse en serio

- En comparación con otros países, los escolares alemanes tienen bastante más experiencia como autores y como víctimas.

En un estudio realizado en Nuremberg en 1994 sobre 20 conductas agresivas o violentas concretas, los resultados arrojaron los siguientes datos: insultos a otros escolares $(82,9 \%$ en chicos, $74,1 \%$ en chicas); peleas con otros escolares ( $48,4 \%$ en chicos, $15,8 \%$ en chicas); difusión de mentiras sobre los compañeros (40,9\% en chicos, $23,0 \%$ en chicas); insultos a profesores no siempre a la cara $(35,6 \%$ en chicos, $32,4 \%$ en chicas); causar daños $(40,1 \%$ en chicos, $27,7 \%$ en chicas); ensuciar (32,0\% en chicos, $31,6 \%$ en chicas); acoso sexual a compañeros $(6,2 \%$ en chicos, $1,6 \%$ en chicas). Además, en las diferentes subpoblaciones del estudio (alumnos de la escuela básica, secundaria obligatoria e instituto, cursos $7^{\circ}, 8^{\circ}$ y $9^{\circ}$ ) los valores de los chicos están siempre por encima de los de las chicas.

La exploración de otras investigaciones llevadas a cabo entre 1990 y 1995 por diversos autores (Lösel y Bliesener, 1990) ha servido para explicar las causas de la violencia escolar. Algunas de ellas serian las siguientes: percibir un claro menoscabo del sentimiento de autoestima y de las oportunidades de un posterior desarrollo de la vida; ciertas características de la personalidad (aislamiento, necesidad de estimulación); la familia de origen (alteración de las relaciones familiares como la falta de cariño, separación y divorcio de los padres, ser hijo único, pobreza y privaciones, educación inestable, agresiva, excesivamente estricta o por el contrario permisiva por parte de los padres, escaso tamaño de la vivienda, jornada laboral completa de los padres); los grupos de coetáneos (pertenencia a un grupo social desviado, pertenencia en el tiempo libre a pandillas informales); la escuela (mal rendimiento escolar, repetición de curso), y el consumo de los medios de comunicación (consumo masivo de películas de acción o terror). Finalmente, cabe señalar la importancia concedida por los jóvenes tanto a los grupos de la misma edad, como a los medios de comunicación, en detrimento de las relaciones sociales tradicionales, como familia, vecindario, asociaciones e Iglesia, lo cual conllevaría una modificación de los estilos de vida, que va acompañada de la pérdida de un sistema homogéneo de valores, 
RIS

provocando actos violentos cuando la desintegración se percibe como pérdida del sentido de la pertenencia, de oportunidades de participación o de identidad. Este aspecto forzaría el impulso de la función educadora de la escuela, al menos como un paralelo que en ocasiones resulta más realista como sustituto de las familias rotas. En este sentido se han empezado a plantear propuestas tales como la de establecer un sistema de vigilancia fuera de las clases o crear escuelas de jornada completa.

Entre las intervenciones a nivel estatal en Alemania cabe mencionar la ya citada Comisión Gubernamental Independiente sobre la Prevención y Control de la Violencia, cuyos inicios se remontan a 1990. Las principales áreas a las cuales se ha dirigido esta Comisión son las siguientes: violencia en la familia, violencia en las escuelas, violencia en los estadios, violencia en las calles y plazas públicas, y violencia motivada políticamente. Sobre la violencia en la escuela se concluyó que no había alcanzado los niveles que reflejaban los informes de Estados Unidos, y se asumió un enfoque multifactorial basado en la interacción de familia, escuela, grupos de pares, medios de comunicación, y personalidad. Dentro de ellos, emergió como factor importante el clima educacional, sobre el cual se cumplimentaron como prevenciones las siguientes actuaciones: recordar a las escuelas su misión educativa, reforzar la responsabilidad de profesores y estudiantes por su escuela, y aminorar la frustración del fracaso escolar mediante la implantación de apoyos adecuados.

\section{Francia}

$\mathrm{Al}$ igual que ocurre en Alemania, en Francia los principales estudios sobre la agresividad continuada entre escolares cabría incluirla en un ámbito de más envergadura, cual es el de la violencia tal como es definida en el Código Penal. La importancia y actualidad del tema se asemeja al de las naciones anteriormente analizadas, como se comprueba a través de la iniciativa del Ministerio de Educación francés de utilizar el primer trimestre del año acadé-mico de 1995-1996 para interrumpir las clases durante dos horas de manera que todos los alumnos pudieran discutir con sus profesores sobre el problema de la violencia en la escuela. De algún modo, con ello se culminaba el esfuerzo investigador del Ministerio de Educación (Dirección de Evaluación y de Prospectiva) en colaboración con el Ministerio del Interior (Estudios sobre Seguridad Interior) y con la supervisión de B. Charlot de la Universidad de San Denis, para que diez equipos se dedicaran a analizar el problema desde diferentes ángulos científicos y sociales: estudios etnográficos, entrevistas por medio de cuestionarios, trabajo de campo, entrevistas y grupos de mediación, observación, planteamientos experimentales, análisis de signos desde una perspectiva criminológica; tales análisis sociológicos han sido complementados por análisis médicos y psicológicos.

Según uno de los estudios más representativos, el desarrollado por C. Carra y 
F. Sicot (1996), se pueden extraer las siguientes conclusiones:

- No existe una única forma de bullying escolar, sino varias.

- Los alumnos normalmente mencionan actos o hechos que son a menudo ignorados cuando se introduce el término bullying: mencionan más y sienten más agudamente la falta de respeto hacia ellos, el daño a su propiedad o el robo, que el acoso sexual, la agresión o el chantaje sistematizado (racketing); por ejemplo, la falta de respeto hacia ellos está mencionado por casi el $50 \%$ de los chicos hostigados, pero sólo el 5\% menciona el chantaje sistematizado.

- La importancia del sentimiento de ser acosado se puede comprobar en que al menos un $69 \%$ de los alumnos decía que habían sido hostigados al menos una vez.

- La sobrerepresentación de muchachos entre 12 y 13 años que se encontraban en el grado final de la primera parte de secundaria.

- La mayor vulnerabilidad de los chicos procedentes de grandes familias (más de 4 hermanos) cuyos padres están divorciados o desempleados, o cuya madre es una inmigrante; en otras palabras, que algunos chicos corren mayor peligro de ser agredidos que otros.

Entre las iniciativas y las intervenciones llevadas a cabo por la Secretaría de Estado de Educación en 1996, cabe señalar las siguientes conclusiones (Fabre-Carnali et al., 2000):

- La mejora y refuerzo de la supervisión de los estudiantes en escuelas con problemas sociales y de violencia, a través de trabajadores sociales, supervisores, cuidadores y jóvenes voluntarios. Cada región académica fue equipada con unidades de apoyo para escuelas con problemas de violencia.

- La ayuda y apoyo de alumnos y de sus padres, de manera que la lucha contra el absentismo escolar se convirtiera en prioritaria.

- La preservación de las escuelas y la mejora de sus alrededores, a partir de medidas tales como que todas las escuelas en zonas de educación prioritarias serían evaluadas, que el mapa de estas escuelas podía ser modificado y que podrían ser adoptadas medidas para limitar el tamaño escolar en zonas deprimidas.

\section{Holanda}

En Holanda cabe destacar la iniciativa del Ministerio de Justicia, el cual en 1993, basándose en el estudio de la bibliografía especializada sobre la eficacia de la educación en la prevención del delito, llegó a la conclusión de que la educación efectiva, interpersonal y continuada, así como el control social (premios y castigos), son más eficaces que las campañas realizadas a través de los medios de comunicación. Desde otro ámbito, como es el de la Secretaría de Estado de Educación, Cultura y Ciencia, se han llevado a cabo diversas actuaciones, como la iniciada en 1994 de designar un comité para elaborar un programa de acción para combatir la violencia en las escuelas. En 1995, este programa se publicó 
R IS

bajo el título Voorkoming en bestijding geweld in scholen (Prevención y Lucha contra la Violencia en la Escuela) al mismo tiempo que se inició una campaña nacional denominada "Escuelas Seguras". En el mismo año, el Ministerio de Salud, Bienestar y Deporte publicó un informe sobre las características de los jóvenes pertenecientes al grupo de riesgo en relación al desarrollo de la conducta antisocial y las políticas al respecto.

\section{Irlanda}

Según la definición del Departamento de Educación en septiembre de 1993, el término bullying es definido como una agresión repetida, verbal, psicológica o física llevada a cabo por un individuo o grupo contra otros; en este contexto los tipos de bullying pueden ser de agresión física, daño a la propiedad, extorsión, intimidación, llamadas telefónicas abusivas, aislamiento, motes y tomar el pelo a alguien. En el contexto irlandés, este último término se refiere a un tipo de intercambio inofensivo que ocurre como un intercambio social entre personas; sin embargo, cuando se extiende a comentarios muy personales dirigidos a una persona una y otra vez acerca de su apariencia, formas de vestir, higiene personal o su familia, especialmente si está camuflado con tintes sexuales, entonces llega a ser una especie de bullying. Desde entonces, el Departamento de Educación ha estado siempre muy activo con este problema, como lo pone de manifiesto el hecho de que formara un grupo de expertos para analizar sus posibles consecuencias en los colegios irlandeses; este grupo estaba formado por un representante del Departamento de Educación, dos inspectores escolares (uno de primaria y otro de secundaria), un representante de los padres y dos representantes universitarios. Las conclusiones del estudio apuntaron hacia la constatación de que el fenómeno bullying estaba mucho más extendido de lo que se pensaba, afectando tanto al aula y al clima general del colegio, como a la comunidad en general. Otras actividades desarrolladas por diferentes instituciones y personas han supuesto la realización de dos conferencias monográficas sobre el tema: una nacional en 1993, y otra internacional en 1996 (recogida en un número monográfico especial del Irish Journal of Psychology de 1997).

De acuerdo con los datos obtenidos por Byrne (1993), existía en la isla un $10,4 \%$ de chicos implicados en la violencia bullying: entre ellos, el 5,3\% como agresores y el $5,1 \%$ como víctimas. Dentro de ese grupo, los chicos tenían más probabilidad de estar involucrados como agresores, que las chicas, ya que, de todos los violentos, sólo una cuarta parte estaba formada por chicas. Las víctimas eran más introvertidas y angustiadas que los agresores, significativamente más neuróticas y a menudo más preocupadas, infelices y miedosas de nuevas situaciones. Los agresores tendían a ser más incontrolados que las víctimas. Un alto porcentaje de profesores expresó que la violencia constituía un problema 
general; sólo una tercera parte lo consideraba como un problema significativo en su propia escuela, y de ellos sólo una minoría (el $5 \%$ ) consideraba que había recibido una buena formación para tratar el problema de la violencia en los colegios. Una buena parte de los profesores consideraba que no era un problema que les afectara personalmente, dado que una gran parte del fenómeno se desarrollaba fuera del espacio de su clase, aunque si así fuera no pensaban que existiera un gran apoyo para ayudarles.

En 1996 fueron presentados los resultados de un estudio realizado en el curso escolar de 1993-94 sobre alumnos de 8 a 16 años en 530 escuelas (de ellas 320 de primaria y 210 de secundaria) subvencionado por la Fundación Gulbenkian y el Departamento de Educación, y encargada a O'Moore, Kirkham y Smith (1997) del Centro de Investigación y Recursos de Trinity College de Dublin. El estudio encontró que 1 entre 20 niños de primaria era víctima una vez a la semana, y 1 entre 50 chicos en la escuela secundaria; asimismo, encontró que el $92 \%$ de los alumnos de secundaria que eran víctimas de la violencia no se lo contaban a nadie.

\section{Estados Unidos}

Los incipientes trabajos de Perry et al., $(1990,1992)$ han sido citados frecuentemente por su descripción del perfil de las víctimas, mostrando la importancia de la estrategia seguida por los alumnos agresores en escoger a aquéllos más propicios. De ahí se deduce que el chico agresivo no distribuye su agresividad eventualmente sobre todos los posibles objetivos, sino que selecciona entre sus compañeros y dirige sus ataques hacia aquella minoría de alumnos que presentan consistencia en su estatus de víctima, incentivado por la percepción del agresor de que sus actos no van a encontrar castigo alguno. Stephenson y Smith (1992), a través de un estudio realizado en Cleveland, encontraron que, cerca de una cuarta parte de los chicos, estaba implicada como agresores o víctimas, y que los malos tratos duraban cerca de un año o más. Asimismo, dicho estudio mostraba que los chicos utilizaban agresiones fisicas directas o una combinación entre físicas y verbales, mientras que las chicas utilizaban medios indirectos y verbales. Las escuelas jugaban un papel esencial, ya que las más pequeñas, que agrupaban alumnos de varias edades, no experimentaban hechos significativos de violencia, mientras que las que se encontraban situadas en áreas deprimidas presentaban mayores ratios de bullying. Otros estudios han explorado las estrategias del género en la violencia, como el realizado por Ross (1996), que mostró que los chicos agresivos pro-activos tienen menos tendencia que otros chicos a establecer metas que favorecen e incrementan la relación mutua durante la interacción social, mientras que las chicas utilizan formas indirectas, tales como exclusión social, ostracismo, propagar maliciosos chismorreos y chivo expiatorio. En el estudio llevado a cabo en la Universidad 
RIS

REVISTA INTERNACIONAL DE SOCIOLOCIA

N*27, Septiembre - Diciembre, 2000

TEODORO HERNÁNDEZ DE FRUTOS

de Illinois por Crick y Grotpeter (1995), se evidenció la denominada agresión relacional, o tendencia de las chicas a deteriorar o manipular las relaciones entre los pares porque éstas suponen la realización de metas que les son importantes (como la conexión íntima).

\section{España}

Las principales investigaciones sobre el fenómeno bullying empiezan en 1989 por medio de un estudio desarrollado por Fernández y Quevedo (1989) sobre 1.200 estudiantes de EGB y Secundaria en Madrid, obteniendo que el $17 \%$ se identificaba como agresores, mientras que el $14 \%$ se identificaba como sufriendo el hostigamiento; las formas más frecuentes de agresión eran las verbales, seguidas de los ataques físicos y robos y daños a pertenencias personales.

La segunda investigación fue realizada por Cerezo y Esteban (1992) sobre 317 alumnos de la región de Murcia distribuidos en 169 chicos y 148 chicas, comprendidos entre los 10 y 16 años. Aplicando un cuestionario Bull, basado en la técnica del sociograma, dicho estudio encontró un $11,4 \%$ de chicos pertenecientes al grupo bully, un $5,4 \%$ al de víctima y un $83,2 \%$ al de otros, lo que significaba que el $16,8 \%$ de los alumnos estaba implicado en la dinámica bullying.

La tercera fue llevada a cabo por Ortega y Mora-Merchan (1999) sobre un proyecto tutelado por K. Smith sobre cinco escuelas de Sevilla aplicando un cuestionario Olweus a 859 alumnos de edades entre 12 y 16 años. Las víctimas eran el $1,6 \%$, mientras que los agresores eran el $1,4 \%$; los considerados como agresores y al mismo tiempo víctimas el $15,3 \%$, y los que no parecían estar implicados en comportamiento bullying, pero jugando el rol de observadores, el $77,4 \%$. En cuanto al género, se comprobó que había más chicas observadoras, $(82,7 \%)$ que chicos (73\%) y que los chicos representaban tres veces más que las chicas en la relación agresor / víctima (20,3\% frente a $9 \%)$.

La cuarta investigación, y sin duda la más importante por el tamaño de la muestra y la dispersión geográfica, ha sido la encargada por el Defensor del Pueblo (2000) en colaboración con UNICEF sobre 3.000 estudiantes de la E.S.O. en España. Los principales resultados sobre las víctimas han mostrado lo siguiente: 1) la exclusión social, medida por el concepto de "ignorar" y por el grado de "en muchos casos me ocurre", sucedía en un $0,9 \%$, pero si es medida por el concepto de "no dejar participar" y por el grado de "en muchos casos me ocurre", suponía el $1,8 \%$; 2) la agresión verbal, medida por tres conductas, como "insultarme", "ponerme motes" y "hablar mal de mí", y con el grado de "en muchos casos", supuso el $4,7 \%, 7,1 \%$, y $3,7 \%$ respectivamente; 3 ) la agresión fisica indirecta ocurría en "esconder cosas" en un 1,8\%, en "romper cosas" en un $0,3 \%$, y en "robar cosas" en un $0,9 \% ; 4$ ) la agresión fisica directa, 
medida por el hecho de "ser pegado por los compañeros" era en "muchos casos" en un $0,7 \%$ y "a veces me ocurre" en un $4,1 \% ; 4$ ) las amenazas y chantajes se producían a través de las "amenazas y meter miedo" en "muchos casos" en un $1,2 \%$, en "obligar a hacer cosas" en un $0,1 \%$, y en "amenazar con armas" en un $0,1 \% ; 5$ ) el acoso sexual suponía el $1,7 \%$ de frecuencia esporádica y el $0,6 \%$ cuando decían que les ocurría "en muchos casos" (Defensor del Pueblo, 2000: 152-153).

Otro estudio que se puede utilizar como termómetro indirecto es el Sistema Estatal de Indicadores de la Educación del Instituto Nacional de Calidad y Evaluación (2000), en donde se pone de manifiesto que, en los centros educativos, coexiste, junto con la organización determinada legislativamente y la específica definida por el mismo centro, una tercera constituida informalmente por las afinidades y relaciones de los diferentes colectivos y miembros que forman parte del centro. Es lo que se conoce como clima escolar, que tiene su reflejo en el nivel de satisfacción de sus miembros. Según una encuesta del INCE en 1997, el clima en las aulas se podía considerar globalmente bueno, siendo las relaciones entre alumnos las que en mayor porcentaje se perciben por el propio alumnado como buenas o muy buenas (el $93 \%$ de los alumnos), seguidas de las relaciones de los alumnos con los profesores (el 76\% de los alumnos). Comparando estas cifras con las relativas a estudiantes de primaria, se puede concluir que aumenta la satisfacción con los compañeros, pero que disminuye la satisfacción con el profesorado. En el marco de la misma encuesta, un $16 \%$ de los padres manifestaba la existencia de conductas agresivas en los hijos.

\section{EL CASO DE NAVARRA}

Se presentan en esta sección los resultados de un estudio encargado por el Instituto Navarro de la Mujer para investigar la violencia del género en la Comunidad Foral en estudiantes de la Educación Secundaria Obligatoria (ESO). Como marco del programa se analizaron algunos de los 81 casos de violencia escolar producidos en el curso 1998-99 en Centros Públicos (54) y Centros Privados (27) que habían sido objeto de apertura de expediente por parte del consejo escolar de cada centro. La evolución de los expedientes abiertos en los centros de la ESO en Navarra no presenta una evolución lineal, ya que el número va aumentando desde el curso 1995-96 hasta el 1997-98, pero al siguiente año decae hasta los 81 casos (ver tabla 1).

La parte cualitativa, compuesta de 10 entrevistas en profundidad a profesores, tutores y directores de Centros de la E.S.O., así como la observación participante en los patios de colegios, han proporcionado el primer material básico para orientar el cuestionario e iniciar un análisis adicional. La fase cuantitativa se 
RIS

REVISTA INTERNACIONAL UE SOCIOLOGIA

No 27, Septiembre - Diciembre, 2000

TEODORO HERNÁNDEZ DE FRUT'OS

fundamenta en una muestra de 603 alumnos/as de una población de 22.073 estudiantes. El nivel de confianza establecido fue del 95,5\%, el error muestral aproximado del $+/-4$ para datos globales, y la varianza poblacional del $50 \%$. La estratificación fue a través de género (varón y mujer), zona geográfica (colapsamiento de Zonas 2000 de Navarra: Noroeste y Pirineo, Pamplona, Comarca de Pamplona, Estella y Navarra Media Oriental, Ribera Alta y Tudela) tipo de escuela (privada o pública), y modelo lingüístico de la enseñanza ( $G$, $\mathrm{A}, \mathrm{y} \mathrm{D})^{4}$. Según los últimos datos del Consejo Escolar del Estado en el curso 1999-2000 siguieron las enseñanzas de Educación Secundaria Obligatoria un total de 1.995 .410 alumnos en todo el Estado, repartidos entre centros públicos (1.325.993) y centros privados (669.417), con una media de 25,6 alumnos por aula en el primer ciclo y 26,7 alumnos por aula en el segundo ciclo. En Navarra había 22.073 alumnos, 12.682 procedentes de la enseñanza pública y 9.391 de enseñanza privada, con una media de 24,4 alumnos por aula en primer ciclo y 23,7 alumnos por aula en el segundo ciclo.

El cuestionario utilizado para la investigación cuantitativa fue básicamente el confeccionado por I. Fernández y R. Ortega (1999) con alguna modificación toda vez que el muestro piloto o pretest indicó una alto absentismo por parte de los alumnos y alumnas a la hora de contestar a ciertas preguntas. Además se incluyó una batería de actitudes machistas que el equipo identificó como relevantes. El muestreo se realizó en el mes de mayo para poder dar cuenta de lo ocurrido durante el curso escolar. Algunos resultados obtenidos fueron los siguientes:

\footnotetext{
${ }^{4}$ Este último se fundamenta en la Ley Foral 18/1986 de 15 de diciembre por la que se divide la Comunidad Foral en tres zonas a efectos lingüísticos: zona vascófona, zona mixta y zona no vascófona. En la primera los alumnos recibirán la enseñanza en la lengua oficial que elija el alumno o sus representantes legales; en la segunda la incorporación del vascuence a la enseñanza se llevará a cabo de forma gradual, mediante la creación en los Centros de líneas donde se imparta enseñanza en vascuence para quienes lo soliciten; en la tercera la enseñanza del vascuence será apoyada y, en su caso, financiada total o parcialmente por los poderes públicos, de acuerdo con la demanda. El Decreto Foral $159 / 1988$ de 19 de mayo, reguló la incorporación y el uso del vascuence en la enseñanza no universitaria de Navarra (Bon, 1988: pp.1-7), estableciendo los siguientes modelos lingüisticos en los centros públicos y privados de la Comunidad: Modelo A (enseñanza en castellano, con el euskera como asignatura), Modelo B (enseñanza de la mayoría de materias en euskera y el resto en castellano), Modelo D (enseñanza en euskera, con el castellano como asignatura), Modelo G (enseñanza en castellano).
} 
Tabla 1

$N^{o}$ de casos de violencia escolar según Inspección de Navarra

\begin{tabular}{lcccc}
\hline Tipo de centros & $1995-96$ & $1996-97$ & $1997-98$ & $1998-99$ \\
\hline Centros públicos & 26 & 59 & 74 & 54 \\
Centros privados & 31 & 39 & 51 & 27 \\
Total casos & 57 & 98 & 125 & 81 \\
\hline
\end{tabular}

Fuente: Consejería de Educación del Gobierno de Navarra.

\section{Hipótesis y contrastación con otros estudios}

\section{Hipótesis 1}

De acuerdo con la teoría existente sobre la existencia del curriculum oculto, de Jackson (1991) y J. Torres (1996), existe un espacio donde se desarrolla la vida escolar de manera no oficial. Llevado hacia la perspectiva de la violencia en los centros escolares, supondría que ésta se desarrolla en lugares alejados del control de los profesores, tutores y personas mayores. Según los estudios de Siann et al., (1994), Whitney y Smith (1993), la frecuencia más alta de las agresiones se produce en el patio del colegio y en la clase, mientras que, según Olweus (1993), la mayor parte de las agresiones se produce en la clase. En ninguna parte se especifica si cuando existe violencia en la clase, es delante del profesor, aunque es de suponer que esto no sea así, por lo que se apoyaría la idea de una violencia oculta en la escuela.

Los lugares donde se producen las escenas de agresión y violencia demuestran que, aunque el orden se mantiene, existen diferencias significativas entre chicos y chicas. Como se observa en la tabla 2, la agresión se produce en cualquier sitio; es decir, no existe un espacio concreto, sino un lugar indeterminado; ello es producto del diseño arquitectónico del centro escolar, con espacios donde resulta complicado la presencia de un mayor. Por lo tanto, hay que concluir que el hostigamiento se produce indiscriminadamente en varias escenas al mismo tiempo, pero que es en la clase, tal como se ha corroborado en las entrevistas en profundidad, donde se produce la chispa; al fin y al cabo, es el lugar donde se invierte más tiempo, por lo que es también donde se desarrolla la mayor parte de las agresiones. Pero, lo que se podría denominar como desenlace final de una pelea o de una agresión importante, es frecuente que ocurra en el patio; al fin y al cabo éste es un lugar donde suele existir menos vigilancia y donde es complicado que alguien medie. 


\section{RIS}

Tabla 2.

Lugares del colegio donde se agrede.

\begin{tabular}{|c|c|c|c|c|c|}
\hline \multicolumn{6}{|c|}{ ¿En qué lugares del colegio se meten con ellos/as? Señala una, la más frecuente. } \\
\hline & \multirow[b]{2}{*}{ Bases } & \multicolumn{2}{|c|}{ Género $(\%)$} & \multicolumn{2}{|c|}{ Centro $(\%)$} \\
\hline & & Varón & Mujer & Público & Privado \\
\hline En ningún sitio & 47 & 9,3 & 6,2 & 11,7 & 3,2 \\
\hline En el patio & 58 & 10,9 & 8,3 & 11,7 & 7,2 \\
\hline En los aseos & 3 & 1,0 & - & 0,6 & 0,4 \\
\hline En los pasillos & 25 & 2,6 & 5,9 & 5,8 & 2,2 \\
\hline En clase & 180 & 24,0 & 36,2 & 27,1 & 33,1 \\
\hline En cualquier sitio & 285 & 51,1 & 43,1 & 42,5 & 52,9 \\
\hline No sabe/No contesta & 5 & 1,3 & 0,3 & 0,6 & 1,1 \\
\hline Total & 603 & \multicolumn{2}{|c|}{100} & \multicolumn{2}{|c|}{100} \\
\hline
\end{tabular}

\section{Hipótesis 2}

En base a la teoría sobre la invisibilidad de las chicas en clase de D. Spender (1983), M. Stamworth (1983) y J. Torres (1996), las chicas no se hacen notar en el aula, por lo que esto supone una pérdida de recursos que va en detrimento de mejorar los resultados. Los chicos, al ser más activos y bulliciosos, reclaman constantemente la atención del profesor en contra de las chicas.

Esta hipótesis es dificil de comprobar empíricamente. No obstante, según las entrevistas en profundidad con los profesores, esto no ocurre. Pero en base a la encuesta, el $17 \%$ de los chicos opinaba que las chicas tienen que estar calladas en clase, mientras que el $81 \%$ opinaba que no, y el resto no contestaba; por parte de las chicas, el $9 \%$ opinaba que las chicas tienen que estar calladas en clase, mientras que un $90 \%$ decía que no, y el $1 \%$ no sabía o no contestaba. Esta clara diferencia entre chicos y chicas sugiere que, por parte de una minoría de alumnos, todavía se piensa en la imagen de la chica callada y subalterna en clase con respecto al chico.

\section{Hipótesis 3}

Los chicos utilizan la violencia y la agresión en una mayor proporción que las chicas; es decir, están más implicados que éstas en el fenómeno bullying, tesis defendida entre otros por Boulton y Underwood (1992), O'Moore y Hillery (1989). Según mantiene Konrad Lorenz en su obra sobre sociobiología, la forma de violencia más típica suele ejecutarse en grupos. 
Las respuestas obtenidas en esta pregunta (tabla 3), apuntan a que funciona la estrategia de grupo, ya que el porcentaje más alto de hostigamiento se produce a través de varios chicos que se meten con los demás; sin embargo, existe una clara distancia en la apreciación de chicos y chicas cuando la agresión la provocan conjuntamente. Cuando existe una agresión individual ésta se encuentra claramente asociada a los chicos, mientras que cuando las chicas intervienen lo suelen hacer en conjunción con otros chicos, lo que podría indicar que las chicas utilizan una estrategia de rentabilizar la fuerza de los chicos para meterse con los demás.

Tabla 3.

Persona que se mete con los demás.

\begin{tabular}{|c|c|c|c|c|c|}
\hline \multicolumn{6}{|c|}{ ¿Es un chico o una chica quien se mete con los demás? Señala sólo una opción. } \\
\hline & \multirow[b]{2}{*}{ Bases } & \multicolumn{2}{|c|}{ Género (\%) } & \multicolumn{2}{|c|}{ Centro (\%) } \\
\hline & & Varón & Mujer & Público & Privado \\
\hline Un chico concreto & 86 & 16,3 & 12,1 & 13,5 & 15,1 \\
\hline Varios chicos & 274 & 48,6 & 42,1 & 44,3 & 46,8 \\
\hline Una chica & 3 & - & 1,0 & 0,9 & 0 \\
\hline Varias chicas & 10 & 1,3 & 2,1 & 1,5 & 1,8 \\
\hline Chicos y chicas & 139 & 16,0 & 30,7 & 24,0 & 21,9 \\
\hline Todo el mundo & 67 & 12,8 & 9,3 & 10,5 & 11,9 \\
\hline No sabe/No contesta & 24 & 5,1 & 2,8 & 5,2 & 2,5 \\
\hline Total & 603 & & & & \\
\hline
\end{tabular}

\section{Hipótesis 4}

De acuerdo con la teoría sexual bullying, sostenida principalmente por D. Olweus (1993), Hoover et al., (1992) y Whitney and Smith, dentro del Proyecto Sheffield (1993), los chicos utilizan una estrategia de intimidación y abuso basada en la fuerza física para dominar a ambos sexos, mientras que las chicas desarrollan una estrategia basada en rumores maliciosos y aislamiento, pero casi exclusivamente dentro de su propio grupo de género. Frente a esta tesis, Neil Duncan (1999) arguye que tanto chicos como chicas no representan grupos homogéneos y que las chicas duras emergen como dominantes incluso sobre algunos chicos; algunas chicas sostienen su poder por su relación con hermanas o hermanos mayores, así como con novios o cuñados. 
R IS

REVISTA INTERNACIONAL DE SOCIOLOCIA

No 27, Septiembre - Diciembre, 2000

TEODORO HERNÁNDEZ DE FRUTOS

De acuerdo con la investigación por observación directa en los patios de recreo y en las clases, y a las entrevistas con los profesores, las chicas nunca están inmersas en ataques que supongan el empleo de la violencia física. Los datos aportados por la tabla 4 indican que no existen diferencias entre chicos y chicas en el maltrato esporádico de alguna vez, mientras que en el maltrato continuo los chicos sobrepasan a las chicas. También se puede observar una mayor magnitud de maltrato en los centros privados frente a los públicos.

Tabla 4.

Intensidad de la violencia sobre los demás.

\begin{tabular}{|c|c|c|c|c|c|}
\hline \multicolumn{6}{|c|}{ Y tú, ¿te metes y/o tratas mal a algún compañero/a?. } \\
\hline & \multirow[b]{2}{*}{ Bases } & \multicolumn{2}{|c|}{ Género (\%) } & \multicolumn{2}{|c|}{ Centro (\%) } \\
\hline & & Varón & Mujer & Público & Privado \\
\hline Nunca & 247 & 35,5 & 46,9 & 44,9 & 36,3 \\
\hline Alguna vez & 332 & 58,5 & 51,4 & 52,3 & 58,3 \\
\hline Más de 4 veces & 11 & 2,2 & 1,4 & 1,2 & 2,5 \\
\hline Casi todos los días & 13 & 3,8 & 0,3 & 1,5 & 2,9 \\
\hline Total & 603 & \multicolumn{4}{|c|}{100} \\
\hline
\end{tabular}

\section{Hipótesis 5}

Muchos estudios han incidido sobre la tipología de violencia que se produce (Olweus, 1993, Smith y Sharp, 1994). En concreto, en la investigación realizada en España por R. Ortega y J. Mora-Merchan (1999), se citaban los siguientes: insultos $(31 \%)$, rumores $(12,2 \%)$, robos $(11,8 \%)$, amenazas $(8,4 \%)$, ataques fisicos $(5,7 \%)$ y aislamiento $(5,5 \%)$.

La manera de meterse con ellos-as adquiere ligeras connotaciones diferenciales entre los géneros y en los centros. Las formas más repetitivas de meterse con los demás (tabla 5) estarían formadas por insultos, reirse, poner motes y meterse fisicamente, existiendo poca variación entre varones y mujeres y entre centros públicos y privados. El chantaje de dinero es la forma que menos se produce. En líneas generales, las chicas perciben mayor violencia que los chicos, sobre todo "el reírse de ellos/as", "dar de lado", "hablar de ellos/as"; es decir, el tipo de violencia que se ha especificado anteriormente como propia de las chicas. 
Tabla 5.

Tipos de agresión (respuesta múltiple).

\begin{tabular}{|c|c|c|c|c|c|}
\hline \multicolumn{6}{|c|}{$\begin{array}{l}\text { ¿Cómo se meten con ellos/as?. Si se meten de alguna forma, } \\
\text { indica tantas respuestas como sea necesario. }\end{array}$} \\
\hline & \multirow[b]{2}{*}{ Bases } & \multicolumn{2}{|c|}{ Género (\%) } & \multicolumn{2}{|c|}{ Centro (\%) } \\
\hline & & Varón & Mujer & Público & Privado \\
\hline No se meten & 67 & 3,7 & 1,9 & 4,9 & 1,0 \\
\hline Les insultan & 371 & 15,6 & 16,0 & 16,2 & 15,4 \\
\hline Se ríen de ellos & 431 & 16,9 & 19,9 & 19,4 & 17,4 \\
\hline Les ponen motes & 359 & 15,3 & 15,3 & 15,5 & 15,1 \\
\hline Se meten fisicamente & 273 & 11,5 & 11,8 & 11,3 & 11,9 \\
\hline Se meten con sus cosas & 122 & 5,5 & 4,9 & 5,1 & 5,3 \\
\hline Les dan de lado & 164 & 5,5 & 8,5 & 6,2 & 7,7 \\
\hline Hablan de ellos & 216 & 8,7 & 9,8 & 8,7 & 9,7 \\
\hline No les dejan participar & 60 & 3,2 & 1,8 & 2,3 & 2,8 \\
\hline Les echan la culpa & 105 & 5,3 & 3,6 & 4,7 & 4,3 \\
\hline Les amenazan & 128 & 5,9 & 5,0 & 4,2 & 6,6 \\
\hline Les chantajean con dinero & 12 & 0,6 & 0,4 & 0,2 & 0,8 \\
\hline Les obligan a hacer cosas & 39 & 2,4 & 0,9 & 1,2 & 2,1 \\
\hline Total & 100 & & & & \\
\hline
\end{tabular}

\section{Hipótesis 6}

Como ya hemos visto, la violencia bullying se caracteriza por unos rasgos que la convierten en especial. Concretamente, podemos presenciar este tipo de violencia cuando alguien está expuesto, de forma repetitiva y durante un tiempo, a acciones negativas que lleva a cabo otro alumno o varios de ellos. Una acción negativa es cuando alguien, de forma intencionada, causa un daño, hiere o incomoda a otra persona mediante el contacto físico. Se pueden cometer acciones negativas de palabra (por ejemplo, con amenazas y burlas, tomar el pelo o poner motes). Comete una acción negativa quien golpea, empuja, da una patada, pellizca o impide el paso a otro. También es posible llevar a cabo acciones negativas sin el uso de la palabra y sin el contacto físico: por ejemplo, mediante muecas o gestos obscenos, excluyendo de un grupo a alguien adrede $o$ negándose a cumplir los deseos de otra persona.

Teniendo en cuenta el problema de la intensidad del bullying, tal como sostiene N. Duncan (1999), podemos resaltar de la encuesta lo siguiente: el 8,6\% de los chicos y chicas navarros atestigua que algún compañero o compañera ha abusado de otros o de otras casi todos los días (de ellos, un 9,6\% son varones y un 7,6\% son mujeres). Mientras que en un nivel algo menor que el anterior, medido por el rechazo que han sufrido los companeros/as por parte del resto, el $17,1 \%$ responde que casi todos los días, dándose una forma más intensa 
RIS

en las chicas que en los chicos, ya que supone el $14,4 \%$ de los varones frente al $20 \%$ de las mujeres.

\section{Hipótesis 7}

El bullying se suele producir por estudiantes de mayor edad. Según M. Eslea (1998), esto constituye el principal temor de muchos estudiantes cuando pasan de la escuela primaria a la secundaria. Otras hipótesis mantienen que la edad es una variable explicativa importante para predecir el bullying, ya que los niños de más edad pueden abusar de los de menos edad, por tener más fuerza y tener más habilidades en cómo ejercer el bullying. La mayor parte, si es que no todos, de los chicos y chicas tendrán experiencias de bullying en algún momento de su vida escolar, ya sea en forma de víctima, en forma de agresor o en forma de testigos. Además, algunos autores, como K. Reid (1989), han citado el bullying como la causa de que algunos alumnos(as) tengan miedo a la escuela y la rechacen.

Esta cuestión se encuentra íntimamente asociada a la pregunta sobre el sitio donde se ejercita la violencia. De acuerdo con la Tabla 6, entre la clase y el curso suponen el $76 \%$ en chicos y el $82 \%$ en chicas, lo cual corrobora la tesis de que la agresión se produce entre iguales. Existe una diferencia fundamental entre chicos y chicas, ya que en los primeros la acción puede proceder de un curso superior, mientras que casi nunca de uno inferior, aspecto que no ocurre con las chicas, cuya diferencia de fuerza posibilita la amenaza de chicos de menor edad que ellas. Otras características de esta situación es que ocurre principalmente desde que "comenzó el curso" (37,5\%), lo que provoca que se sienta miedo al acudir al colegio "alguna vez" en el $27 \%$, y "casi todos los días" en el $0,2 \%$, y que el $11 \%$ diga que es por temer a "algún compañero/os".

Tabla 6.

Procedencia del que comete la agresión.

\begin{tabular}{|c|c|c|c|c|c|}
\hline \multicolumn{6}{|c|}{ ¿Dónde está quien se mete con ellos/as?. Señala sólo una opción, la más frecuente. } \\
\hline & \multirow[b]{2}{*}{ Bases } & \multicolumn{2}{|c|}{ Género (\%) } & \multicolumn{2}{|c|}{ Centro (\%) } \\
\hline & & Varón & Mujer & Público & Privado \\
\hline En ningún sitio & 82 & 16,6 & 10,3 & 18,5 & 7,9 \\
\hline Es de mi clase & 296 & 47,0 & 51,4 & 43,1 & 56,1 \\
\hline Es de mi curso & 182 & 29,1 & 31,4 & 29,8 & 30,6 \\
\hline Ee de un curso superior & 34 & 6,7 & 4,5 & 6,5 & 4,7 \\
\hline Es de un curso inferior & 9 & 0,6 & 2,4 & 2,2 & 0,7 \\
\hline Total & 603 & \multicolumn{2}{|c|}{100} & \multicolumn{2}{|c|}{100} \\
\hline
\end{tabular}




\section{Hipótesis 8}

Dado que el estudio estaba referido a la violencia bullying en general y a la que se produce entre chicos y chicas en particular, pareció oportuno introducir una escala de actitudes "machistas" relacionadas con el fenómeno estudiado. Después de haber preguntado a varios expertos en el tema y haber testado cientos de ítems, se confeccionó una escala de 9 ítems, cuyos resultados se incluyen en la Tabla 7. a) Existe una gran diferencia entre la opinión de chicos y chicas en todos los ítems excepto en los números $3,4,6 ; b$ ) donde parece existir una gran coincidencia es en las preguntas 4 y 6 ; c) los más contestados positivamente son los ítems 4, 6 y 1 , y los menos contestados positivamente son los ítems 3, 7, y 2; d) donde existe un mayor distanciamiento en las opiniones es en los ítems 9, 1,7 y 8 ; e) un tercio de los chicos todavía cree que las mujeres están mejor adaptadas para cocinar y planchar que los hombres. Los porcentajes de los centros privados indican una menor inclinación machista que los públicos.

Tabla 7.

Actitudes ante ideología machista (contestaciones positivas).

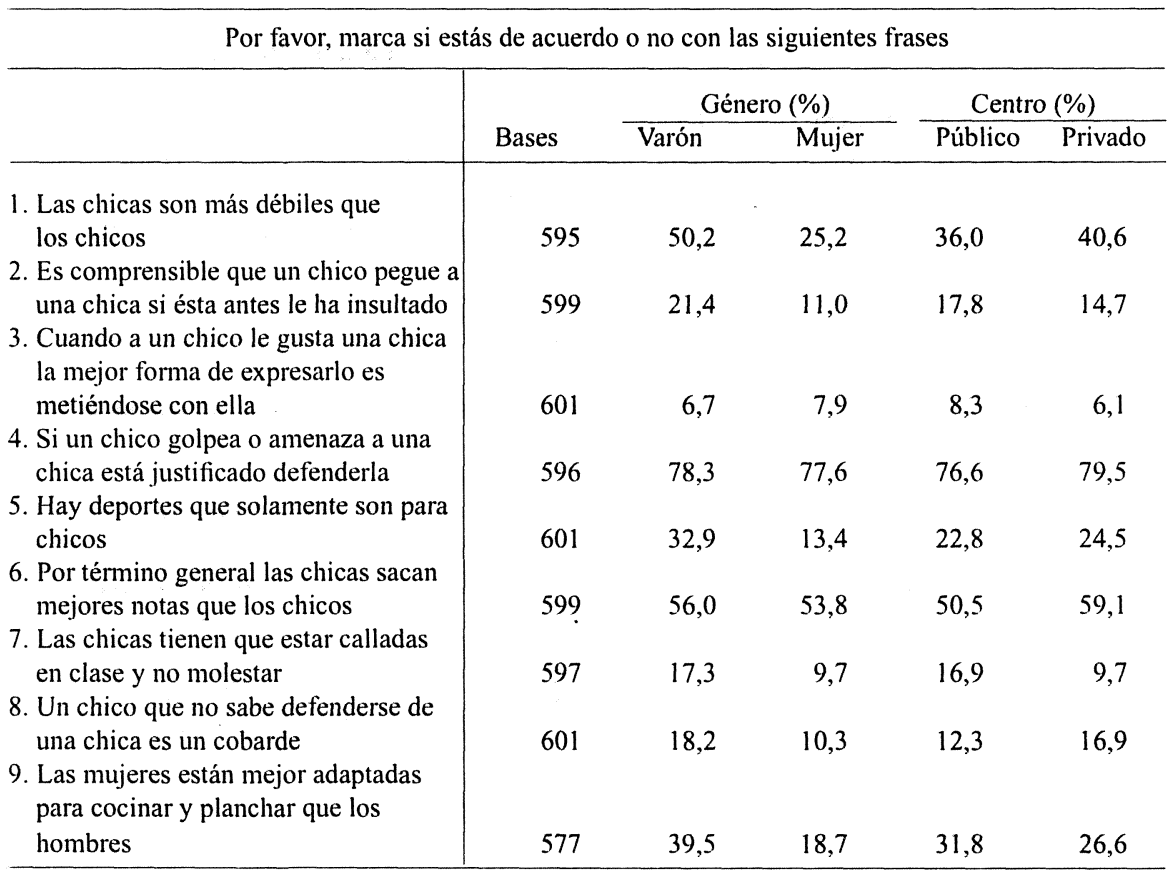




\section{BIBLIOGRAFÍA}

AHMAND, Y. y P. SMITH (1994), "Bullying in schools and the issue of sex differences", en J. Archer (ed.), Male violence, London, Rouletledge.

BESAG, V. (1989), Bullies and victims in schools, Philadelphia, Open University Press.

BJORKQVIST, K. et al. (1992), "Do girls manipulate and boys fight? Develop-mental trends in regard to direct and indirect aggression", Aggressive Behavior, $\mathrm{n}^{\circ} 18, \mathrm{pp} .117-127$.

BOULTON, M. y K. UNDERWOOD (1992), "Bully/victim problems among middle school children", British of Educational Psychology, n 62, pp. 73-87.

BOWLES, S. y H. GINTIS (1981), La instrucción escolar en la América capitalista. La reforma educativa y las contradicciones de la vida económica, México, Siglo XXI.

BYRNE, B. (1993), Bullies and victims in a school setting with reference to some Dublin schools, $\mathrm{Ph}$. D. Thesis, University College Dublin.

(1999), "Ireland", en P.K. Smith et al. (ed.), The nature of school bullying, London, Routledge, pp. 112-127.

CARRA, C. y F. SICOT (1996), Pour un diagnostic local de la violence à l'école. Enquete de victimation dans les collèges du département du Doubs. Laboratoire de sociologie et d'anthrolologie, Université de Franche-Comté.

CEREZO, F. (1998), Conductas agresivas en la edad escolar, Madrid, Pirámide.

CEREZO, F. y M. ESTEBAN (1992), "La dinámica bully-victima entre escolares: diversos enfoques metodológicos”, Revista de Psicología Universitas Tarraconensis, n 14. pp. 131-145.

CRICK N. y J. GROTPETER (1995), "Relational aggression, gender, and social-psychological adjustement", Child Development, n 66, pp. 710-722.

CHESNAIS, J.C. (1994), Histoire de la violence, París, Hachette.

DEBARBIEUX, E. (1997), "La violencia en la escuela francesa: análisis de la situación, políticas públicas e investigaciones", Revista de Educación, n³13, pp. 79-93.

DEFENSOR DEL PUEBLO (2000), Informes, estudios y documentos, Madrid, Defensor del Pueblo.

DUNCAN, N. (1999), Sexual bullying. Gender conflict and pupil culture in secondary chools, London, Routledge.

ELLIOT, D. et al. (1998), "Violence in American schools: an overview", en D. Elliot et al. (ed.), Violence in american schools, New York, Cambridge University Press, pp. 3-31.

ESLEA, M. (1998), "The long-term effectiveness of anti-bullying work in primary schools", Educational Research, vol. 40, n², pp. 203-218.

100 
FABRE-CORNALI, D. et al. (1999), "France", en P.K. Smith et al. (ed.), The nature of school bullying, London, Routledge, pp. 129-139.

FAWCETT, B. et al. (ed.) (1996), Violence and gender relations, London. Sage.

FERNÁNDEZ, I. y G. QUEVEDO (1999), "Violence, bullying and counselling in the Iberian Peninsula: Spain”, en I. Fernández (coord.), Prevención de la violencia y resolución de conflictos, Madrid, Narcea, pp. 215-219.

FERNÁNDEZ, M. (1995), La escuela a examen, Madrid, Pirámide.

FRENCH, J. (1986), Gender and the classroom, New Society, $\mathrm{n}^{\circ} 7$.

FUNK, W. (1997), "Violencia escolar en Alemania. Estado del arte”, Revista de Educación. $\mathrm{n}^{\circ} 313$, pp. 53-77.

GLOVER, D. et al. (1997), Anti-bullying in action. Keele. University of Keele.

(2000), "Bullying in 25 secondary schools: incidence, impact and intervention", Educational Research, vol. 42, $\mathrm{n}^{\circ} 2$, pp. 141-156.

HOOVER, J. et al. (1992), "Bullying: perceptions of adolescent victim in the Midwestern USA", School Psychological International, n¹3, pp. 5-16.

INCE (2000), Sistema estatal de indicadores de la educación, Madrid, Ministerio de Educación, Cultura y Deporte.

JACKSON, P. (1991), La vida en las aulas, Madrid, Morata.

JUNGER-TAS, J. (1999), "The Netherlands", en Smith P. K. et al. (Ed.). The nature of school bullying, London, Routledge, pp. 205- 224.

LAGERSPETZ, et al. (1982), "Group aggression among school children in three schools", Scandinavian Journal of Psychology, $\mathrm{n}^{\circ} 23, \mathrm{pp} .45-52$.

LÖSEL, F. y T. BLIESENER (1999), “Germany”, en P.K. Smith et al. (ed.), The nature of school bullying, London, Routledge, pp. 205-224.

LOWENSTEIN, L.F. (1978), "The bullied and no-bullied child", Bulletin of the British Psychological Society, no 31 , pp. 316-318.

OLWEUS, D. (1978), Aggression in the schools: bullies and whipping boys, Washington, Hemisphere. (1993), Bullying at school. What we know and what we can do, Oxford, Blacwell.

(1998), Conductas de acoso y amenazas entre escolares, Madrid, Morata.

(2000), "Sweden", en P.K. Smith et al. (ed.), The nature of school bullying, Routledge, London, pp. 7-28. 


\section{RIS}

O'MOORE, A. y B. HILLERY (1989), "Bullying in Dublin schools", Irish Journal of Psychology, $n^{\circ} 10$, pp. $426-441$.

O'MOORE, A. et al. (1997), "Bullying behaviour in Irish schools: a nation-wide study", Irish Journal of Psychology, $\mathrm{n}^{\circ}$ 18, pp. 141-169.

ORTEGA, R. (1994), "Violencia interpersonal en los centros educativos de enseñanza secundaria. Un estudio sobre maltrato e intimidación entre compañeros", Revista de Educación, n" 304, pp. 253- 280.

ORTEGA, R. y J. MORA-MERCHAN (1999), "Spain", en P.K. Smith et al. (ed.), The nature of school bullying. A cross-national perspective, London, Routledge, pp. 157-174.

PERRY, D. et al. (1990), "Peers'perceptions of the consequences that victimized children provide aggressors", Child Development, $\mathrm{n}^{\circ}$ 61, pp. 1.310-1.325.

PERRY, D. et al. (1992), "Conflict and the development of antisocial behavior", en C. Shantz and W. Hartup (ed.), Conflict in child and adolescent development, New York, Cambridge University Press, pp. 301-329.

REID, K. (1989), "Bullying and persistent school absenteism", en D. Tattum and D. Lane (ed.), Bullying in schools, Stoke on Trent, Tretham Books.

ROLAND, E. y E. MUNTHE (Ed.), Bullying: an international perspective, London, David Fulton, pp. 41-52.

ROLAND, E. (1989), "Bullying: the scandinavian research tradition", en D. Tattum and D. Lane (ed.), Bullying in schools, Stoke on Trent, Trentham Books.

SCHÄFER, M. (1996), "Aggression unter Scülern. Eine Bestandsaufnahme über das Schikanieren in der Scuke am Beispiel der 6 und 8. Klassenstufe", Report Psychologie, n² 21, pp. 700-711.

SIANN, G. et al. (1994), "Who gets bullied? The effect of school, gender and ethnic group", Educational Research, $\mathrm{n}^{0} 36$, pp. 123-134.

SMITH, P.K. y S. SHARP (1994), School bullying: insights and perspectives; London, Routledge.

SPENDER, D. (1983), Invisible women: schooling scandal, London, Women's Press.

STANWORTH, M. (1983), Gender and schooling, London, Hutchinson.

STEPHENSON, P. y D. SMITH (1988), "Bullying in the junior school". en D. Tattum y D. Lane (ed.), Bullying in schools, Stoke on Trent, Trentham Books.

(1992),"Why some schools don't have bullies", en M. Elliot (ed.), Bullying: a practical guide to coping for schools, Essex, Longman, pp. 133-145.

SUBIRATS, M. (1999), "Género y escuela", en C. Lomas (ed.), ¿Iguales o diferentes?, Barcelona, Paidós, pp. 19-33.

102 
SUBIRATS, M. y C. BRULLET (1988), Rosa y azul. La transmisión de los géneros en la escuela mixta, Madrid, Instituto de la Mujer.

SWAIN, J. (1998), "What does bullying really mean?", Educational Research, vol. 40, n" 3 , pp. 359- 364 .

TATTUM, D. y G. HERBERT (1990), Bullying: a positive response, Cardiff, SGIHE Learning Resources Centre.

TORRES, J. (1996), El curriculum oculto, Madrid, Morata.

WHITNEY, I. y P. SMITH (1993), "A survey of the nature and extent of bullying in junior/middle and secondary schools", Educational Research, n 35, pp. 3-25.

WHITNEY, I. et al. (1994), "The Sheffield Project: methodology and finding", en P. Smith y S. Sharp (ed.), School bullying, London, Routledge, pp. 20-57.

WHITNEY, I. y P. SMITH (1993), "A survey of the nature and extent of bullying in junior/middle and secondary schools", Educational Research, n"35. pp. 3-25.

SUMMARY. This article is an account of a study carried out in Navarra on the subject of "bullying" among secondary education (ESO) students within a 14-16 year old age range. The main characteristic of this type of violence is its repetition in time and by the same actors and victims. Gender relations were also measured, as were the different forms of bullying practiced by groups of boys and girls. According to the results, this fenomenon far from disappearing, is still an important practice in the daily routine of the schools in Navarra. Teachers don't tend to have uniform solution to this problem, which corresponds to the area know as the "hidden curriculum".

E-mail: theo@unavarra.es 